\title{
Designing and adapting tasks in lesson planning: a critical process of Lesson Study
}

\author{
Toshiakira Fujii ${ }^{1}$
}

Accepted: 23 February 2016 / Published online: 14 March 2016

(C) The Author(s) 2016. This article is published with open access at Springerlink.com

\begin{abstract}
There is no doubt that a lesson plan is a necessary product of Lesson Study. However, the collaborative work among teachers that goes into creating that lesson plan is largely under-appreciated by non-Japanese adopters of Lesson Study, possibly because the effort involved is invisible to outsiders, with our attention going to its most visible part, the live research lesson. This paper makes visible the process of lesson planning and the role and function of the lesson plan in Lesson Study, based on case studies conducted by Project IMPULS at Tokyo Gakugei University in three Japanese schools. The paper identifies key features of the planning process in Lesson Study, including its focus on task design and the flow of the research lesson, and offers suggestions for educators seeking to improve Lesson Study outside Japan.
\end{abstract}

Keywords Lesson study · Lesson planning · Task design · Structured problem solving

\section{Introduction}

While the history of Lesson Study in Japan spans more than a century (Makinae, 2010), for Japanese educators, Lesson Study is like air, part of everyday school life. This situation possibly explains why Lesson Study is regarded as being under-theorised (e.g. Elliott, 2012). Educators outside Japan however, having had to learn about Lesson Study less naturally, may sometimes lose some important aspects of Lesson Study.

Toshiakira Fujii

tfujii@u-gakugei.ac.jp

1 Tokyo Gakugei University, Tokyo, Japan
Lesson Study came to the attention of educators outside of Japan primarily through the publication of The Teaching Gap (Stigler and Hiebert, 1999), which described findings from the TIMSS video study focussing on the eighth grade mathematics lessons in USA, Germany, and Japan. Chapter seven in particular, titled "Japan's approach to the improvement of classroom teaching", which is based on Yoshida's (1999) doctoral dissertation, now available in book form (Fernandez and Yoshida, 2004), provoked enormous interest, not only in Lesson Study, but also in the typical structure of Japanese mathematics lessons. Independently, some educators such as Lewis also noticed the significance of Japanese Lesson Study (Lewis and Tsuchida, 1998).

Since then many mathematics teachers and teacher educators around the world have been involved in Lesson Study, and many books and research papers have been written on various aspects of Lesson Study (Lewis, 2002; Lewis et al., Lewis and R, Perry., \& J. Hurd, 2009; Hart, Alston and Murata, 2011; Doig and Groves, 2011; Department for Children, Schools and Families, 2008; White and Lim, 2008; Ono and Ferreira, 2010). However, some aspects of Lesson Study, that may be taken for granted by Japanese teachers, seem not to be well understood outside Japan.

This paper aims to clarify the role and function of lesson planning in the Lesson Study process, based on case studies conducted in three schools in Tokyo.

\section{Background}

\subsection{The Lesson Study process}

Lesson Study is an approach to teacher professional development that differs sharply from the professional 
Table 1 Contrasting views of professional development (Liptak, cited in Lewis, 2002, p. 12)

\begin{tabular}{ll}
\hline Traditional professional development & Lesson Study \\
\hline Begins with answer & Begins with question \\
Driven by outside "expert" & Driven by participants \\
Communication flow: trainer to teachers & Communication flow: among teachers \\
Hierarchical relations between trainer and teachers & Reciprocal relations among learners \\
Research informs practice & Practice is research \\
\hline
\end{tabular}

development practices common in other countries. Liptak (cited in Lewis, 2002, p. 12) contrasted Lesson Study with traditional professional development as practised in the United States, as shown in Table 1.

Lesson Study begins with a question, not with an answer prepared by someone else. Identifying this question, which becomes the research theme for Lesson Study, is the first step in the process (see Fig. 1).

The research theme is developed through consideration of the reality of students' current state vis-à-vis educational or long-term goals for their learning and development.

The second step of Lesson Study is to develop a plan to address the research theme through lessons. This means making an instructional plan for a selected unit and a detailed plan for one of the lessons in that unit in which the planning team puts forth their ideas about how to address the research theme while teaching specific academic content. That lesson is called the research lesson.

The third and fourth steps in Fig. 1, conducting the research lesson and having a detailed discussion about the lesson, occur in one day - a big event day for the school. Typically, it is done in a half day; one class of students stays for the research lesson while the other classes are dismissed so that every teacher can come to observe the research lesson (even the school nurse and school nutritionist usually attend). At the end of the post-lesson discussion, usually there will be final comments lasting $30 \mathrm{~min}$ or more by a "knowledgeable other" from outside the school, who has been invited for this purpose.

The fifth step is to reflect on the process and consolidate and carry forward the learnings from it. Teachers will usually write their reflections and publish records of Lesson Study activities in the school bulletin.

Because they are the most visible aspects of Lesson Study, some people think of the research lesson and postlesson discussion as the most important parts of Lesson Study, or even use "Lesson Study" to refer to the research lesson alone. However, these are just two of the five components of Lesson Study.

The Lesson Study cycle, with its five steps as illustrated in Fig. 1, contrasts with similar diagrams in other publications that have four steps (e.g. Lewis, 2002; Lewis and Hurd, 2011). These five steps, while overlapping with the four steps in the other diagrams, more

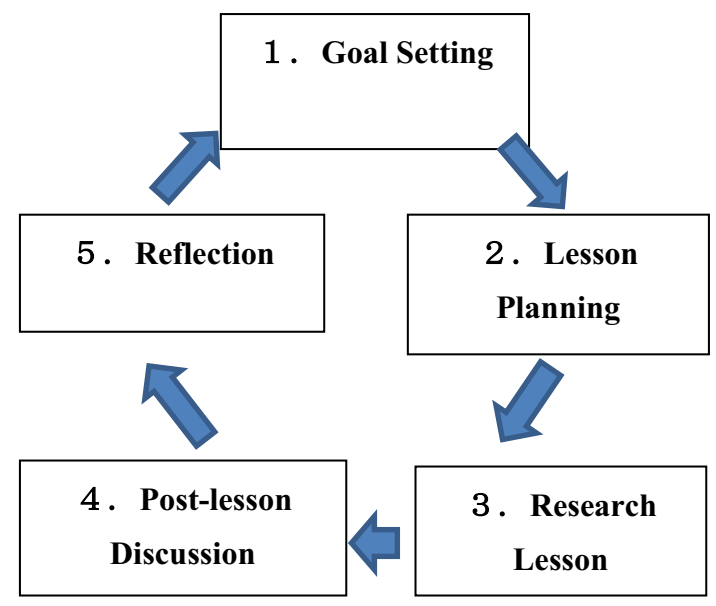

Fig. 1 The process of Lesson Study (Fujii, 2014a, p. 113)

accurately portray the reality of Japanese teachers' Lesson Study activity by having a closer correspondence between the titles of the steps and the activities undertaken by teachers.

Borrowing from Lewis' (2002) and Lewis and Hurd's (2011) descriptions, each step can be summarized as follows:

1. Goal setting Consider long-term goals for student learning and development. Identify gaps between these long-term goals and current reality. Formulate the research theme.

2. Lesson planning Collaboratively plan a "research lesson" designed to address the goals. Prepare a "lesson proposal" - a document that describes the research theme, content goals, connections between the current content and related content from former and later grades, rationale for the chosen approach, a detailed plan for the research lesson, anticipated student thinking, data collection, and more.

3. Research lesson One team member teaches the research lesson while the other members of the planning team, staff members from across the school, and, usually, an outside knowledgeable other observe and collect data.

4. Post-lesson discussion In a formal lesson colloquium, observers share data from the lesson to illuminate stu- 
dent learning, disciplinary content, lesson and unit design, and broader issues in teaching and learning.

5. Reflection Document the cycle to consolidate and carry forward learnings, as well as new questions for the next cycle of Lesson Study. Write a report or bulletin that includes the original research lesson proposal, student data from the research lesson, and reflections on what was learned.

There are three types of Lesson Study in Japan: Schoolbased, District-based, and National-level Lesson Study. According to Takahashi (2006), participants' motivations or interests are different in these types of Lesson Study, but the cycle itself is basically the same. The difference is in the range, or scope, of students to be considered: school-based Lesson Study is concerned with students in the school; District-based Lesson Study is concerned with students in the district; and National-level Lesson Study is concerned with the reality of students across the country, and has a research theme with a nationwide view. Lesson Study is sometimes introduced as an open lesson by a veteran teacher "jumping in" to another teacher's classroom (Takahashi, 2013, p. 84). A "jumping in" lesson is just a demonstration unless the veteran teacher has a clear goal for the lesson as in Step 1, and proposes a new idea or content to be teachable, or he or she wants to demonstrate students' potential to be greater than ordenary teachers believe, so that he, or she, plans the lesson carefully as in Step 2. This kind of Lesson Study exists in Japan and in this case the collaboration among teachers is not a critical part of Lesson Study. In any case, each step in the Lesson Study cycle is closely related to the others, with the third and fourth steps particularly related to the first and second.

In school-based Lesson Study, which is the focus of this paper, the typical Lesson Study cycle begins at the end of an academic year-i.e. in February or March in Japanwhen the faculty decides upon a research theme for the next school year, which starts in April. Several research lessons are scheduled from, say, May to November. Each research lesson and its post-lesson discussion occupy only one day, but the teachers reflect on what they learned at the research lessons and usually write a booklet or long summary report by the end of school year.

While the importance of a lesson plan as a product of Lesson Study is certainly understood, compared to the research lesson, of which there are many public examples, the collaborative work of Japanese teachers in creating a lesson plan is generally mysterious, because it is difficult to observe. According to Lee and Takahashi (2011) "Lesson plans are central resources for these teachers in that they constantly refer to, problematize and act on them during the entire cycle of the [Lesson Study] procedure" (p. 210).
Japanese teachers spend a lot of energy and time crafting a lesson plan. Although the details vary from school to school and even from teacher to teacher, Lewis (2002, pp.127-130) notes that a typical template for a lesson plan for a research lesson in Japan consists of the following:

1. Name of the unit

2. Unit objectives

3. Research theme

4. Current characteristics of students

5. Learning plan for the unit, which includes connections to standards and to prior and subsequent learning, the sequence of lessons in the unit and the tasks for each lesson, and explanation of unit "flow"

6. Plan for the research lesson

7. Background information and data collection forms for observers (e.g. a seating chart)

The Japanese term for the document created for a research lesson is gakushushido-an (学習指導案), which is usually translated as "lesson plan". In this paper we will use that common translation, although we prefer the phrase "lesson proposal", because the document is much larger and broader in scope than what is usually meant by "lesson plan". Also the word "plan" may imply a fixed script, but in Japanese Lesson Study the teacher is expected to use his or her judgment if students respond in unanticipated ways. As Lee andTakahashi (2011) argue, researchers have taken for granted that using lesson plans, no matter how well devised, always involves judgment and interpretation, as teachers and their students face the contingencies of the lesson in the classoom. Their empirical study, in the context of Lesson Study, provided analytic descriptions of the interactive processes through which lesson plans are realized, leading to the conclusion that "classroom teachers use lesson plans as communicative resources to identify problems, specify assumptions about their teaching, and act on the evolving contingency of classroom interaction" (p. 209). However, Lee and Takahashi (2011) did not describe details of planning the lesson, including how teachers adapted or designed the task for the lesson, or how many hours they spent on planning.

In the context of Lesson Study, Lewis, Perry and Hurd (2009) focussed on one US lesson study group, of six teachers from five different schools, that conducted a research lesson in a 2-week summer workshop. This is an experimental situation, which is different from the Japanese traditional school-based Lesson Study setting. However it is worth considering in terms of the lesson planning activity. They documented that the group spent a total of six hours planning the lesson: "select research lesson, do task and share solutions, anticipate student thinking, write instructional plan using template" (Lewis et al., 2009, p. 
290). However they have not offered descriptions of how they designed or adapted the task for the lesson.

On the other hand, Fernandez and Yoshida (2004) described in detail the process of planning lessons in the context of Lesson Study. This ethnographic study, focussed on a local elementary school in Hiroshima, vividly shows Japanese teachers' activities. However, the Lesson Study described there has the rather unique feature in that, following the research lesson being taught by a young inexperienced teacher, observed by the whole school and discussed by only the lower grade group of teachers and the principal, the lesson was revised by these teachers and then re-taught by a veteran teacher, with the whole school and an ouside advisor observing the lesson and taking part in the postlesson discussion. The notion of Re-Teaching is extremely problematic and sensitive. In fact, the need to revise and re-teach a lesson is one of the misconceptions identified in foreign countries implementing Japanese Lesson Study (Fujii, 2014b). Whether Re-Teaching exists or not in the Lesson Study process affects the nature of the planning and the discussion of the lesson.

\subsection{Structured problem solving}

The structure of Japanese mathematics lessons is often regarded as unique by non-Japanese eyes, with researchers from outside Japan having noted patterns in Japanese mathematics lessons. For example, Becker et al. (1990) identified eight components in a typical Japanese mathematics lesson, while Stigler and Hiebert (1999) identified five components and labelled these lessons as structured problem solving. But their points of view are those of observers, while Japanese teachers usually do not think about the structure of their lessons in the same way. For instance, the first component of Stigler and Hiebert (1999), reviewing the previous lesson, is not an important activity from a Japanese teacher's point of view. Instead Japanese teachers typically consider a mathematics lesson as problem solving in terms of the four phases shown in Table 2 (see, for example, Shimizu, 1999).

This type of lesson imposes certain demands on how to interpret the lesson plan. Phase 1, presenting the problem, means helping students understand the context of the problem or task and what it will mean to solve the taskbut it specifically excludes any exposition by the teacher about how to solve the task. Instead, students are expected to work independently on the task for 10-20 min (phase

Table 2 The four phases of a problem-solving lesson in mathematics

1. Presenting the problem for the day (5-10 min)

2. Problem solving by the students (10-20 $\mathrm{min})$

3. Comparing and discussing (neriage) (10-20 min)

4. Summing up by the teacher (matome) ( $5 \mathrm{~min}$ )
2). Therefore teachers need to discuss the appropriateness of the task described in the lesson plan. The third phase, called neriage in Japanese, assumes that students will arrive at different solution methods and focusses on a comparison and discussion of those different solution methods. Therefore teachers need to discuss the plausibilty of the anticipated student solutions listed in the lesson plan. In the fourth phase, matome, the teacher may say something about which strategy may be the most sophisticated and why, but it should go beyond that to include comments by the teacher concerning the mathematical and educational values of the task and lesson (Fujii et al., 1998). Therefore teachers need to discuss the resonableness of the matome by the teacher as foreshadowed in the lesson plan. For a lesson to work in this way, the task should be understandable by the students with minimal teacher intervention; it should be solvable by at least some students (but not too quickly), and it should lend itself to multiple strategies.

This paper focusses on the second, planning step in the Lesson Study cycle, and aims to illuminate the nature of the collaborative work among teachers, based on three case studies where re-teaching was not part of the Lesson Study process, with particular emphasis on planning for these four phases of the research lessons.

\section{Methodology}

This research took place in three local public elementary schools in Tokyo, which will be referred to as schools M, S and $\mathrm{T}$. These schools were participating in the International Math-teacher Professionalization Using Lesson Study project (IMPULS), a recently established project funded by the Ministry of Education, Culture, Sports, Science and Technology of Japan, located at Tokyo Gakugei University, Tokyo. The purpose of this project is two-fold. First, as an international centre of Lesson Study in mathematics, Tokyo Gakugei University and its network of laboratory schools help teacher professionals learn about authentic Japanese Lesson Study, and thereby prepare them to create Lesson Study systems in their own countries for long-term, independent, educational improvement in mathematics teaching. Second, the project conducts research projects examining the mechanism of Japanese Lesson Study in order to maximize its impact on schools in Japan.

Although several research lessons were scheduled for each year, this study focusses on just one research lesson at each of these schools, and the planning meetings for those research lessons-that is, just one lesson study cycle in each school.

The author observed each lesson-planning meeting and took fieldnotes. In addition, each lesson-planning meeting was video-recorded and later transcribed; and all lesson 
plans and revised versions were collected and analyzed with respect to their evolution.

This paper provides a descriptive analysis of the planning process undertaken by these groups of teachers in preparation for the research lessons. In a similar vein to the research carried out by Lee and Takahashi (2011), discourse-in-interaction analysis (Sacks et al., 1974) was used to examine "the methods and procedures by which participants carry out ordinary tasks of classroom teaching and collaboration among teachers" (Lee and Takahashi, 2011 , p. 215). The analysis began with unmotivated looking (Sacks, 1992) during the observations of the planning meetings in order to identify key discussions that eventually led to consensus regarding the lesson plans.

Through this overview of the lesson planning processes, the author came to realize that the discussions were based on the flow of the lesson. In particular, it seemed that teachers could imagine or visualize clearly what would happen at the research lesson through reading the lesson plan. Therefore it was clear that this study could focus on analyzing the planning of the flow of the research lesson.

Based on the flow of Japanese problem-solving lessons, thematic content analysis (see, for example, Fereday and Muir-Cochrane, 2006; Braun and Clarke, 2006) was carried out on transcripts of the lesson planning discussions. Using the framework of the four phases of problem-solving lessons (Table 2), participants' comments were coded with appropriate keywords to track their views of the lessons. These comments were examined with respect to the role of the lesson plan and planning meetings, in order to make visible an important part of Lesson Study — namely the planning process.

The following section is organized according to the main results obtained through the inductive process of examining the trajectory of revising lesson plans, transcribed records of planning meetings, research lesson, and post-lesson discussion, and field notes.

\section{Results}

The results of this study are presented in three sections. First, we report on the lesson planning meetings overalle.g. the number of meetings and participants, and the duration of meetings. Second, we examine the major component of the meetings. Finally, we identify major concerns at the meetings, such as the appropreateness of the task for the lesson, anticipated student solutions, and how to organize the comparison and discussion phase in the lesson.

\subsection{The lesson planning process overall}

The dates of the research lessons held at school M, S and T, together with the dates of the planning meetings are shown
Table 3 Dates of research lessons and planning meetings

\begin{tabular}{llllll}
\hline & Meeting 1 & Meeting 2 & Meeting 3 & Meeting 4 & $\begin{array}{l}\text { Research } \\
\text { Lesson }\end{array}$ \\
\hline School M & 15 May & 22 May & 13 June & 21 June & 1 July \\
School S & 30 May & 6 June & 11 June & 19 June & 3 July \\
School T & 28 May & 4 June & & & 26 June \\
\hline
\end{tabular}

Table 4 Number of participants at the planning meetings

\begin{tabular}{lllll}
\hline & Meeting 1 & Meeting 2 & Meeting 3 & Meeting 4 \\
\hline School M & 7 & 8 & 8 & 8 \\
School S & 5 & 6 & 7 & 4 \\
School T & 8 & 8 & & \\
\hline
\end{tabular}

in Table 3. The planning meetings began between 4 and 6 weeks before the research lessons. Two schools, $\mathrm{M}$ and $\mathrm{S}$, had four planning meetings and school $\mathrm{T}$ had just two meetings.

It should be noted that there was no rehearsal or trial implementation of a tentative lesson plan between planning meetings. It should be noted also that this schedule fails to reveal the amount of time that the teachers may have spent thinking about their research lesson beforehand, since the grade, unit, and lesson may have been selected at the end of the previous academic year in March.

Table 4 shows the number of participants at each of the planning meetings.

In the case of school $\mathrm{M}$, the regular members of planning meetings were: the leader of the research steering committee, who also chaired the meeting and was the lead teacher for mathematics in the school; three Grade 3 teachers, one of whom taught the research lesson; and four Grade 4 teachers-a total of eight participants. The first planning meeting, held in the principal's office, was rather informal, since the knowledgeable other, who had given a talk at a research lesson that day, joined the meeting, together with the principal of the school. Beside these two participants, three Grade 3 teachers and two Grade 4 teachers attended. But at later meetings, in the school conference room, the only participants were the eight regular members.

At school S, which is a small school with only one class at each grade, the first meeting included five regular members: two classroom teachers for Grades 5 and 6, the music teacher, the art teacher, and the teacher for mathematics. The Grade 6 teacher was the leader of the school research steering committee and taught the research lesson. In Tokyo, in the case of mathematics only, if a school wants to divide classes into two or three groups for teaching mathematics, in order to help cater for individual differences, 
Table 5 Duration of planning meetings (min)

\begin{tabular}{llccll}
\hline & Meeting 1 & Meeting 2 & Meeting 3 & Meeting 4 & Total time \\
\hline School M & 30 & 128 & 114 & 81 & 353 \\
School S & 60 & 60 & 30 & 54 & 204 \\
School T & 78 & 87 & & & 165 \\
\hline
\end{tabular}

the school gets an extra teacher-in this case this teacher. The music teacher and the art teacher were teaching Grade 5 and 6 students, therefor the regular members were the upper year level team. At the second meeting, the principal joined them; at the third meeting, the knowledgeable other also joined; but the fourth meeting included only the Grade 1 teacher and the Grade 6 teacher, the music teacher, and a special needs teacher-these four constituted the school research steering committee. The venue was always a meeting room in the school.

At school $\mathrm{T}$, regular members were the leader of the research steering committee, three Grade 3 teachers and three Grade 4 teachers, and the principal of the school, who attended the planning meetings-so the total number was 8. One of the Grade 4 teachers taught the research lesson. There were only two meetings, both of which were held in the principal's office.

School M, S, and T each organized a research steering committee. According to Takahashi and McDougal (2014), a research steering committee in Japan consists of representatives of each grade level and, in the case of the Lesson Study focussing on mathematics, the lead teacher for mathematics. In addition, representatives of special subject teams, such as music, science and home economics may join. The research steering committee leads the school's efforts and maintains the cohesion of ideas across the grades. Takahashi and McDougal (2014, p. 16) list roles and functions of research steering committees as follows (parenthesis added by author):

- Developing a master plan for the school research;

- Scheduling and leading monthly meetings to find strategies to address the school's research theme based on the ideas of the teachers;

- Publishing a monthly (not always the case) internal newsletter to record the findings from each research lesson;

- Planning, editing, and publishing the school research reports, including those for the research open house; and

- Arranging for knowledgeable others to present lectures, teach demonstration lessons (not always the case), and give final comments at research lessons.

As shown in Table 5, the duration of the planning meetings ranged from a minimum of $30 \mathrm{~min}$ to a maximum of $128 \mathrm{~min}$.
The chairperson of the school research steering committee led most of the meetings at schools $\mathrm{M}, \mathrm{S}$, and T. As these schools were conducting Lesson Study focussing on mathematics, the lead teacher for mathematics tended to also be in charge of the school research steering committee. Besides regular members from the school, the knowledgeable other, who had given comments on a research lesson that day, attended the first meeting at school $\mathrm{M}$ and the third meeting at school S. Involving a knowledgeable other in this way is common; after a research lesson and discussion ends, the team responsible for the next research lesson will meet with the knowledgeable other for further discussion and to get advice for their lesson.

As both of the 30-min meetings were with the knowledgeable other, these could be regarded as atypical. The average duration was 72 min, with the average duration excluding the 30 -min meetings being $83 \mathrm{~min}$.

One reason that may account for the differences in the duration of planning meetings between schools could be that the principals of schools $\mathrm{S}$ and $\mathrm{T}$ attended and participated actively in these meetings, with teachers in both schools appearing to have great confidence in them. When teachers asked, these principals gave suggestions to help break deadlocks. As a result, the duration could become shorter. In the case of school M, some of the regular members of planning meetings were young and inexperienced. Therefore, the leader of the research steering committee, who was also the lead teacher for mathematics, sometimes needed to explain the position of the lesson in the scope and sequence of the Japanese course of study, and the mathematical value of the task for use in the lesson. These factors may have had an effect on the longer duration of the meetings.

\subsection{Major components and structure of the planning meetings}

The first meetings held at school $\mathrm{M}$ and $\mathrm{S}$ were unusual in that the teachers discussed ideas about the research lesson in depth without a written lesson plan. At all other meetings, the discussion was based on a draft lesson plan, which had been written, either with or without the support of colleagues, by the teacher who would be teaching the lesson. Furthermore, the flow of the planning meetings followed the flow of the lesson plan. Other issues, such as the logistics of the research lesson or post-lesson discussion, were not discussed.

The format of the first draft of the lesson plan for schools M, S, and T was basically the same as Lewis' (2002) template as described earlier in this paper. In the case of school M, component 5 in Lewis' (2002) template, Learning plan for the unit, was missing at the beginning, but was added later. 
Among the seven components in Lewis' (2002) template, component 6, Plan for the research lesson-which we will refer to here as Planning the flow of the research lesson in order to distinguish it from the overall lesson plan-is the most prominent in terms of both quantity and quality. At school T, the draft lesson plan had already been prepared for the first meeting, written by the teacher who was to teach the research lesson. The items discussed at the first meeting were as follows:

1. The research theme of the school (8 min).

2. The goal of the unit; evaluation points for learning (i. Interest, Eagerness, and Attitude; ii. Mathematical Way of Thinking; iii. Mathematical Skills; and iv. Knowledge and Understanding); the relationship between this unit and the research theme; other units related to this unit; students' reality; and teachers' vision of ideal students (6 min).

3. What ideal students would look like (11 min).

4. Unit and lesson plans (2 min).

5. Planning the flow of the research lesson $(51 \mathrm{~min})$

These items were exactly the items written in the draft lesson plan.

In both meetings at school $\mathrm{T}$, discussion relating to planning the flow of the research lesson occupied the majority of the time: $51 \mathrm{~min}(65 \%)$ of the first meeting as shown above, and $87 \mathrm{~min}(78 \%)$ of the second meeting.

At school S, the first meeting was held without a written lesson plan. At this stage, teachers had not yet decided exactly which unit or content to teach for the research lesson and how. From the second meeting onwards, the teachers' discussions were based on the lesson plan drafted by the teacher who was to teach the research lesson. The knowledgeable other attended the third meeting. Excluding the first and third meetings, the proportion of time spent on planning the flow of the research lesson was $74 \%$, while when all four meetings are included, $52 \%$ of the time was spent on planning the flow of the research lesson.

At school M, the first meeting was also held without the written lesson plan. From the second meeting onwards, the discussion was based on the draft lesson plan which had been written mainly by the teacher who was to teach the research lesson, but as a team, with support from the third grade teachers. In the second, third and fourth meetings, the proportion of time spent planning the flow of the research lesson was $74 \%$, while if the first meeting is included the proportion was $66 \%$. Across the three schools, omitting meetings without the lesson plan, the average proportion of time spent on planning the flow of the research lesson was $72 \%$; while if all meetings are included the proportion was $63 \%$.
Thus we have two findings: one, that the planning meetings followed the structure of the lesson plan; and two, that the discussion among teachers was particularly focussed on planning the flow of the research lesson.

The discussions specific to the flow of the research lesson during the planning meetings at the three schools could be aligned with the four phases of a problem-solving lesson (see Table 2). For example, at the second meeting at school $\mathrm{S}$, a discussion on how students might grasp the given task (15 min) was related to phase 1, Presenting the problem for the day; discussion about likely student responses (14 min) was related to phase 2, Problem solving by the students; discussion about how to organize the comparison and discussion period (15 min) was obviously related to phase 3 , Comparing and discussing; and discussion about how to conclude the lesson (5 min) was related to phase 4, Summing up by the teacher. Of the 49 min focussed on the flow of the research lesson, the proportions of time related to these four phases was approximately 31, 29, 31 and $10 \%$. The other two schools showed a similar pattern.

In the next section we will present, in more detail, what the teachers talked about regarding each phase of their lessons.

\subsection{Major concerns when planning the flow of the research lesson}

Discussions by the teachers, while planning the flow of the research lesson, were classified into three key categories: Appropriateness of the task, Plausibility of the anticipated student solutions, and Quality of the comparison and discussion (neriage) phase.

\subsubsection{Appropriateness of the task}

Discussions about the task for the research lesson can be classified into two types. One is discussion about the task and unit from an advanced mathematical perspective, where teachers clarify the scope and sequence of relevant topics, or relationships within and expansion of the content. The second is to discuss the appropriateness of the task to the goal of the lesson, including detailed consideration of the numbers in the task, the context of the task, and so on.

When teachers talked about the position of the unit within the curriculum, they carefully referred to the National Course of Study (2008) published by the Ministry of Education, Culture, Sports, Science and Technology. According to Lewis' (2002) typical lesson plan template, this discussion is related to "connections to standards and prior and subsequent learning", which is included in the fifth componentof the template, Learning plan for the unit, where related units in former and later grades are explained and shown by using a diagram. In fact, teachers at school 
$M$ used their own diagram as they discussed why the unit was important and as they traced the students' learning path leading to the unit. In the case of school S, at the second meeting where teachers talked about sequence of units, they recalled an old version of the National Course of Study (1998) in which "speed" was placed in fifth grade. "Speed" was now in sixth grade in the National Course of Study (2008). In fact, one teacher said "At fourth grade we teach multiplication and division of decimal numbers, and in fifth grade we teach the size of per-unit quantities. ${ }^{1}$ The closest content to speed is size of per-unit quantities.... We used to teach speed in fifth grade, together with the size of per-unit quantities".

Teachers also talked a lot about the task itself. The tasks in all three cases were not directly from textbooks; they were newly created, or modified from tasks in the textbook. Teachers discussed why they selected the particular tasks; what roles the tasks were expected to play in the unit; what benefits students might gain from solving the tasks: whether it helped to develop a new concept, a new way of thinking, or some important procedure.

The discussion of the curriculum was closely related to the solution of the task, because related content in the curriculum was expected to be a resource for students to solve the task. For example, in the second meeting in School S, there was the following exchange:

Teacher A: $\quad$ Students learned how to arrange to get the same numbers for time or distance, didn't they?

Teacher B: $\quad$ Yes, I suppose. However, the idea of a common multiple was learned a long time ago from the students' point of view.

Teacher C: Probably they forgot the procedure to find the common multiple.

Teacher B: When they learned division of decimal numbers, they learned the idea of perunit. It's the same thing here. However, the idea of per-unit was not learned in the context of comparing things.

Principal: $\quad$ The idea of per-unit quantity was applicable for comparing crowdedness. That is a mathematical way of thinking that could be applicable for Speed.

\footnotetext{
${ }_{1}$ A per-unit quantity is a ratio of two quantities from different measure spaces. As a ratio, it is expressed as the amount of one measured quantity for one unit of the other measured quantity. For example, population density is typically expressed as the number of people per unit area, or speed as the distance travelled per unit time.
}

This kind of detailed and concrete consideration of previously-learned content was observed in all three schools.

Teachers also engaged in detailed discussions about the task itself, including which numbers to use and why. This aspect of Lesson Study was noted by Stigler and Hiebert (1999), who reported that teachers would talk about the "problem with which the lesson would begin, including such details as the exact wording and numbers to be used" (p. 117). However, the selection of numbers is not always from a purely mathematical point of view.

For example, in the case of School S, teachers thought about numbers both in terms of their students' reality and also from a procedural or calculation point of view. The teacher who would teach the research lesson said:

Child A in the problem can run 40 metres in only $6 \mathrm{~s}$.

In my class there is no such fast runner. However I decided to use these numbers, because these numbers are easier for children to calculate.

Time and distance data for the first three people in the problem (A, B, C) were not changed, but data for two people (E, F) were changed from $\mathrm{E}$ (42 metres in $6.7 \mathrm{~s}), \mathrm{F}(28$ metres in $4.9 \mathrm{~s})$ to $\mathrm{E}$ ( 45 metres in $6.5 \mathrm{~s}), \mathrm{F}$ (50 metres in $8 \mathrm{~s}$ ), in order to provide some faster speeds. Numbers for $\mathrm{D}, \mathrm{E}$, and $\mathrm{F}$ were considered hard for students to calculate and the teachers also worried about having decimal fractions as the result of calculations. However, they decided to keep the numbers and let students use calculators if they wanted.

In the case of school M, the task was to contrast partitive and quotitive division problems obtained from one mathematical sentence. The teachers chose to use $8 \div 2$ after also discussing $12 \div 3,18 \div 6,6 \div 2$, and $10 \div 2$ as possible candidates. They considered the numbers 8,2 , and 4 as the most easily distinguishable for students, so that students would not confuse them in using, or explaining, their ideas.

In the case of school T, the research lesson was on learning about quadrilaterals and the task was to classify quadrilaterals. The teachers changed the plan from asking students to draw figures freely on dot paper to giving students figures already drawn by the teacher. The teacher worried that students might not construct certain figures that the teacher particularly wanted to discuss in the lesson. The teachers also discussed what would be a suitable number and what types of quadrilaterals to give. If the number of figures was too small, students would not be interested in classifying them, or they would not feel any necessity to make groups. Eventually the teachers decided on nine figures: a square, a rectangle, two parallelograms, two rhombi, an isosceles trapezium, a general trapezium, and a general quadrilateral. The team decided not to include a trapezium with a right angle. As part of their discussion, teachers simulated individual students solving the problem to get an 
idea of the time required. Further, they considered the quality of the problem-solving activity in terms of the appropriateness of the task and the goal of the lesson.

At all three schools, the teachers discussed the unit in reference to the curriculum, as well as discussing the main task in terms of its appropriateness within the unit, its value for clarifying mathematical ideas, and its appropriateness for accomplishing the goal of the lesson. In terms of the appropriateness of the task for the goals of the lesson, teachers considered what solutions or ideas the students would be likely to bring up. This is the topic of the next section.

\subsubsection{Anticipated student solutions}

In all three schools, teachers spent time discussing likely student responses to the main task in the research lesson. These discussions usually began by considering what was most likely from the class as a whole. They then went on to consider likely responses from students who were rather slow learners and from students who were fast learners.

In the case of school S, teachers pretended to be students in order to solve the speed task, Who is faster? (see Table 6), from the students' point of view. Through this activity, teachers confirmed the plausibility of the four anticipated solutions already written in the lesson plan: (1) finding a common multiple of distance to compare; (2) finding a common multiple of time to compare; (3) finding the amount of time per metre to compare; and (4) finding the distance per second to compare.

In the case of school $\mathrm{T}$, one teacher was asked to pretend to be a student to solve the task, and the other teachers watched his activity. In the case of school M, teachers wondered whether students would be able to create two kinds of division stories or just one story. The team leader asked the other teachers if they felt uneasy partly because of their own experiences. Teachers made explicit reference to their own experiences as they tried to anticipate students' responses to the task.

In all three schools, teachers considered how to deal with slow learners. In the case of school S, the teacher had already decided to provide hints to students who wanted them during the individual problem-solving period. The team discussed specifically what should be on these hint

Table 6 The task given: Who is faster? Let's think about the order of speed of these 3 children: A, B and C

\begin{tabular}{lll}
\hline Children & Distance $(\mathrm{m})$ & Time $(\mathrm{s})$ \\
\hline A & 40 & 6 \\
B & 30 & 6 \\
C & 30 & 5 \\
\hline
\end{tabular}

cards. While a hint card suggesting using common multiples was reasonable from the teachers' initial point of view, they no longer thought this might be the case when they imagined, or visualized, the lesson. They thought this strategy would eventually be rejected in favour of a better strategy: finding the distance per second. One teacher said, "Students might ask the teacher, "Why did you not give me the best hint, if you knew?'” The other teachers agreed that was likely to happen. So they discussed how to let students notice the per second strategy. Finally teachers thought of using 30 metres and $5 \mathrm{~s}$ as the data. "It divides beautifully". "If the teacher asks a question such as, "Five seconds to go $(30 \mathrm{~m})$, so if it were one second how far could you go?, students may be able to notice the idea of per second". "It will work," one teacher said, "it looks fine". Eventually the teacher decided to suggest using the "per second method" to solve the task using the data of 30 metres and $5 \mathrm{~s}$.

In all three schools, teachers also considered how to deal with fast learners in the lesson. For instance, at school M, a teacher said, "Students who have finished solving the task, I would ask them to write mathematical sentences, possibly like $4 \times 2=8$ or $2 \times 4=8$, showing the process to get the answer".

\subsubsection{The comparison and discussion (neriage) phase}

The comparision and discussion (neriage) phase follows the problem solving by the students. This phase in the structured problem-solving lesson is the most difficult for teachers to deal with. Each correct solution has equal value in terms of getting an answer. However, the ideas involved may not have equal value. The neriage phase is when the teacher elicits these ideas and discusses the value of each solution. The teacher at school S clearly stated, "Although each strategy is sure to get the correct answer, we should not end there ... I want the students to know that getting the answer is not the final goal".

In the case of school $\mathrm{M}$, teachers wanted students to compare two word problems, for partitive and quotitive division, through the use of multiplication sentences to model situations. (See the "Appendix" for the actual task.) The lead teacher of the research steering committee posed the question, "What should we ask to elicit a multiplication maths sentence?" For the next $17 \mathrm{~min}$ the teachers discussed what the question should be, including its exact wording.

At school T, teachers talked about which point or theme for discussion would be best: the number of groups of quadrilaterals, where the teacher might say "this student made two groups and the other student made three groups, what made these difference? What were the thoughts behind these categorizations?" or how to characterize each group, for example "This student made two groups. Can 
you see the common characteristics of the quadrilaterals in each group?" One teacher asked, "Which is the higher level of thinking?" to which another teacher responded, "Probably the number of groups is higher. This point is proposed in the lesson plan". So they decided to ask students to discuss how many groups there were and reasons behind this in the neriage phase.

The teams at all three schools discussed how to elevate students' mathematical thinking by comparing individual students' solutions.

\section{Discussion}

It is well known that Japanese teachers get together before a research lesson to discuss the lesson. What do teachers discuss? This study reveals that their discussions followed the lesson plan, which had been drafted or created before meetings, and they devoted approximately two thirds of the time to discussing the flow of the research lesson. Within that time, teachers focussed on the appropriateness of the task, anticipated student solutions, and the plan for comparing and discussing those student solutions. The teachers also referred to the Japanese National Course of Study and its guide for teachers.

\subsection{The role of the Japanese National Course of Study in designing and adapting the task for the research lesson}

At planning meetings, teachers frequently referred to the National Course of Study when they needed to confirm the role of the unit, or focus lesson, within the entire curriculum. Teachers at school $\mathrm{S}$ talked about the placement of speed in the previous National Course of Study. This is a more difficult conversation to have in countries lacking a clear curriculum. Lewis and Tsuchida (1998) argued that having a frugal, shared curriculum was necessary for implementing Lesson Study. With a clear curriculum sequence, teachers could identify the value of the research lesson and the unit within the curriculum: by identifying closely related content in former and later grades, teachers can understand why the research lesson is important for later learning. And, identifying similar units or content in earlier grades helps teachers infer what students might do to solve the task, based on their previous learning. All three teams of teachers identified the position of the research lesson in the curriculum in order to clarify students' learning trajectory.

\subsection{The value of discussing anticipated solutions}

Data from the three schools revealed that teachers tried hard to anticipate student solutions in detail; and what they anticipated influenced the design of the lesson. For example, it influenced the design of the task, such as in the case of school $\mathrm{T}$ where the decision whether to include a trapezium with a right angle was made through considering students' anticipated solutions. Anticipating student responses also influenced how teachers decided to pose the problem. For instance, teachers at school S considered how students would react to the question of which person is faster when only times were given. Also teachers tried to predict students' difficulties, and discussed how to reduce students' confusion in comparing three speeds. They eventually decided to erase the slowest person's data in order to focus on only two people.

Based on their experience, Japanese teachers know that the conditions, or characteristics, of the task influence students' thinking processes and solution methods. In the case of school $\mathrm{T}$, the teachers thought that the right angle might cause students to go in a direction that was not consistent with the goal of the lesson. Anticipating student solutions at planning meetings is therefore important in Lesson Study, and this unique activity is a characteristic of task design in Lesson Study (Fujii, 2015).

Teachers also think carefully about the numbers used in a task because this can strongly influence students' ways of solving the task. In the case of school S, teachers deliberately chose awkward numbers for the additional speed data, of persons D, E, F. The teacher explained, "I want students to say that it is awkward to calculate common multiples among them". She deliberately chose numbers that would push students to calculate distance divided by time. On the other hand, the numbers for $\mathrm{B}$ and $\mathrm{C}$ were $(30,6)$ and $(30$, 5) respectively, with these chosen because the numbers "divide beautifully". The teacher clearly anticipated that some students would calculate $30 \div 6$ and $30 \div 5$ to get the distance per second.

Close attention to the specific numbers does not mean that teachers are sticking to a concrete level of thinking or encouraging students to think concretely. On the contrary, teachers consider the general aspect of the numbers-their quasi-variable aspects. A quasi-variable is a number deliberately used in a general way, so that it serves as a representative of many numbers, just as a variable would (Fujii and Stephens, 2001, 2008; Fujii, 2008, 2010). Numbers are often chosen based on their quasi-variable power, or how well they can demonstrate a general truth-a general truth that is brought out during whole class discussion.

A structured problem-solving lesson includes a neriage - comparison and discussion-phase for students to compare or experience their friends' methods and discuss similarities and differences between strategies as a whole class. When designing the task, there needs to be consideration of whether the task will elicit the alternative approaches needed for an effective neriage. Therefore 
teachers carefully discuss and choose appropriate numbers for the task.

Discussing students' anticipated solutions while considering the specific numbers in the task clarifies the mathematical value of the task. In their book The Teaching Gap Stigler and Hiebert (1999, p. 118) have another example: teachers discuss appropriate number sentences to use in the context of teaching subtraction across 10 . Subtraction across 10 can be solved by subtraction-addition (e.g. $12-9=10-9+2$ ), subtraction-subtraction (e.g. $12-9=12-2-7$ ), counting down, and counting up. In this example, the teachers believed that the subtraction-addition strategy was the most valuable for students to learn, so they examined the potential of different choices of numbers to lead to that strategy. For the same reason, almost all textbooks in Japan choose 13-9 or 12-9 to elicit the subtraction-addition strategy (Doig, Groves, and Fujii, 2011). In the case of school S, numbers were chosen to lead students to calculate distance divided by time. In the case of school T, teachers chose geometrical figures which could lead students to classify them in terms of characteristics related to their parallel or perpendicular sides. Anticipating student solutions in Lesson Study helps clarify the mathematical value of the task, and helps teachers make sure that the goal of the lesson is reached.

\subsection{The value of designing the neriage phase of the lesson}

The comparison and discussion of multiple student solutions needs to be more than "show and tell" (Takahashi, 2008). This neriage phase of a lesson should be an actualization of Vygotsky's zone of proximal development (Ohtani, 2014), and the role of the teacher is critical. Teachers at the three schools, M, S, and T, discussed at length how to deepen students' ideas in the neriage phase. A teacher at school S said, "Although each strategy is sure to get the correct answer, we should not end there". This comment shows teachers' deliberate efforts to elevate all students' ways of thinking.

During the planning meetings, the focus of designing the neriage phase of the lesson was on deepening students' understanding and ways of thinking. From the point of view of mathematical value, the lesson should clarify the relative value of the different solutions, generally by contrasting these. The lesson is less likely, obviously, to do this without sufficiently rich and diverse solutions to compare. Therefore, teachers carefully examine anticipated student solutions in detail in order to make sure valuable solutions are likely to appear in the comparison and discussion phase. The value of designing the neriage phase of the lesson lies in its potential to elucidate or expose ways to highlight different solutions, and how to compare them in order to reach the goal of the lesson.

\subsection{Designing and adapting tasks in lesson planning goes with lesson evaluation}

As we have seen, teachers give much thought to the selection and design of the task during the planning phase of Lesson Study. The task is later evaluated during the postlesson discussion. This is another distinguishing aspect of Lesson Study. The task is not judged based on some abstract determination of whether it is good for teaching a certain skill or concept, but based on concrete evidence from the research lesson of how the students responded to it. In the case of school S, three pairs of data points were added for students to compare, but at the post-lesson discussion teachers argued about whether these additional data were useful or not. The arguments were based on how students actually responded to the task in the lesson. Similar arguments occurred at the other two schools.

In the case of school $\mathrm{S}$, the arguments progressed from evaluating the task to modifying the task. In fact, the final commentator, the knowledgeable other, suggested more direct ways to manipulate numbers to identify faster speed without calculating six pairs of numbers. He gave the example shown in Table 7 of two pairs of numbers in the context of population density:

The final commentator suggested using these numbers instead the six pairs of numbers that were used in the research lesson, as some students struggled to carry out the calculations in the time available, and then missed the educational value of the task, and the whole-class discussion. The post-lesson discussion provided a context for revising the task used at the research lesson, since points missed in planning meetings were revealed in the post-lesson discussion. This shows that the planning meetings of the Lesson Study cycle are closely related to the research lesson itself, and to the post-lesson discussion.

The post-lesson discussion provided a context for revising the task used at the research lesson. However, this does not imply that re-teaching is necssarily part of Japanese Lesson Study. Based on their experience, Japanese teachers know that if students are different then their reactions will be different. They understand that a lesson is itself an organic system, it is not like a machine. A non-organic system, such as a car, is composed of parts that may be easily replaced. However, in organic systems, like a lesson, each part supports the whole ecology. In the case of school S,

Table 7 An example of two pairs of numbers used in the context of population density

\begin{tabular}{lll}
\hline Pool & Area $\left(\mathrm{m}^{2}\right)$ & Number of people \\
\hline A & 200 & 15 \\
B & 400 & 45 \\
\hline
\end{tabular}


important ideas missed in planning meetings were revealed in the post-lesson discussion. Teachers then regretted that their kyozai-kenkyu (study or research on teaching materials - see, for example, Watanabe, Takahashi, and Yoshida, 2008) was not profound enough and broad enough to cover the idea. In other words, Japanese teachers' attitude towards research lessons and lesson plans is that their best lesson plan should be implemented at a research lesson, and that a research lesson is the proving ground for teachers (c.f. Lewis and Tsuchida, 1998).

\section{Conclusion}

It is widely understood that a lesson plan is an important product of Lesson Study, but despite much research into Lesson Study, the process of creating a lesson plan, as a collaborative effort by teachers, is largely invisible to non-Japanese adopters of Lesson Study. This paper tries to clarify the process of lesson planning and the role and function of the lesson plan, based on case studies of Lesson Study in three Japanese schools.

In each of these case studies, we see that the planning meetings began with a lesson plan already written by the teachers and most of the time was spent discussing the flow of the research lesson. While discussing the flow of the research lesson, teachers spent time designing and adapting the task for the lesson, during which time they typically did the following: consulted the National Course of Study to clarify the position of the task in curriculum, as well as for guidelines in designing and adapting tasks; verified the mathematical value of the task by anticipating student solutions; carefully designed the comparison and discussion (neriage) phase of the lesson to ensure that the goal of the lesson was reached.

In addition, teachers evaluated the task during the postlesson discussion in light of the actual student responses in the research lesson, and they also explored how the task might be revised based on this discussion.

Some potentially interesting aspects of lesson planning were not addressed in this paper: the author did not consider the relationship between the quality of the lesson planning and the quality of the research lesson. This paper did not look at the impact of lesson planning on teachers' mathematical and pedagogical knowledge (Lee and Takahashi 2011, Lewis 2009). And the paper did not look at how the lesson planning process exposes teachers' beliefs. The author hopes, however, that by making aspects of the planning phase of Lesson Study visible, this paper will contribute to helping educators outside Japan appreciate the full richness of Lesson Study, and better understand how it can improve teaching and learning.
Acknowledgments The author would like to thank Thomas McDougal for reading and editing numerous revisions and for his invaluable comments on this paper.

\section{Appendix}

The task given by the teacher was: "let's write word problems that can be solved by $8 \div 2$. Draw a picture or diagram for the problem situation. Also, write an equation and the answer, too."

A: $\quad$ Division to find the group size (partitive division) 2 people are sharing 8 strawberries. How many strawberries does each person get? Equation: $8 \div 2=4$ Answer: 4 strawberries

B: Division to find the number of groups (quotative division)

We are going to give 2 strawberries to each person. If there are 8 strawberries, how many people will get strawberries?

Equation: $8 \div 2=4$ Answer: 4 people.

Open Access This article is distributed under the terms of the Creative Commons Attribution 4.0 International License (http://creativecommons.org/licenses/by/4.0/), which permits unrestricted use, distribution, and reproduction in any medium, provided you give appropriate credit to the original author(s) and the source, provide a link to the Creative Commons license, and indicate if changes were made.

\section{References}

Becker, J. P., Silver, E. A., Kantowski, M. G., Travers, K. J., \& Wilson, J. W. (1990). Some observations of mathematics teaching in Japanese elementary and junior high schools. Arithmetic Teacher, 38(2), 12-21.

Braun, V., \& Clarke, V. (2006). Using thematic analysis in psychology. Qualitative Research in Psychology, 3(2), 77-101.

Department for Children, Schools and Families (2008). Improving practice and progression through Lesson Study: Handbook for headteachers, leading teachers and subject leaders. Nottingham: DCSF Publications. Retrieved 27 September from $2011 \mathrm{http} / / /$ teachfind.com/national-strategies/improving-practice-and-progression-through-lesson-study-handbook-headteachers-le

Doig, B., \& Groves, S. (2011). Japanese Lesson Study: Teacher professional development through communities of inquiry. Mathematics Teacher Education and Development, 13(1), 77-93.

Doig, B., Groves, S., \& Fujii, T. (2011). The critical role of task development in Lesson Study. In L. C. Hart, A. S. Alston, \& A. Murata (Eds.), Lesson Study research and practice in mathematics education (pp. 181-199). Dordrecht: Springer.

Elliott, J. (2012). Developing a science of teaching through Lesson Study. International Journal for Lesson and Learning Studies, 1(2), 108-125. 
Fereday, J., \& Muir-Cochrane, E. (2006). Demonstrating rigor using thematic analysis: A hybrid approach of inductive and deductive coding and theme development. International Journal of Qualitative Methods, 5(1), 80-92.

Fernandez, C., \& Yoshida, M. (2004). Lesson Study: A case of a Japanese approach to improving instruction through school-based teacher development. Mahwah, NJ: Lawrence Erlbaum.

Fujii, T. (2008). Knowledge for teaching mathematics. Plenary talk at the 11th international congress on mathematical education, Monterrey, Mexico, July 6-13.

Fujii, T. (2010). Designing tasks in the Japanese Lesson Study: Focusing on the role of the quasi-variable. In Proceedings of the 5th East Asia regional conference on mathematics education EARCOME5, Tokyo, Japan (pp. 86-93).

Fujii, T. (2014a). Theorizing Lesson Study in mathematics education as an emerging research area (2): Identifying components and its structure of Lesson Study (in Japanese). In Proceedings of second annual spring conference of Japan Society of Mathematical Education (pp. 111-118).

Fujii, T. (2014b). Implementing Japanese Lesson Study in foreign countries: Misconceptions revealed. Mathematics Teacher Education and Development, 16(1), 65-83.

Fujii, T. (2015).The critical role of task design in Lesson Study. ICMI Study 22: Task design in mathematics education (pp. 273-286)

Fujii, T., Kumagai, K., Shimizu, S., \& Sugiyama, S. (1998). A crosscultural study of classroom practices based on a common topic. Tsukuba Journal of Educational Study in Mathematics, 17, 185-194.

Fujii, T. \& Stephens, M. (2001). Fostering an understanding of algebraic generalization through numerical expressions: The role of quasi-variables. In H. Chick, K. Stacey, J. Vincent, \& J. Vincent (Eds.), Proceedings of the 12th ICMI study conference: The future of the teaching and learning of algebra (pp. 258-264). Melbourne: University of Melbourne.

Fujii, T., \& Stephens, M. (2008). Using number sentences to introduce the idea of variable. In Algebra and algebraic thinking in school mathematics. National Council of Teachers of Mathematics, Seventeenth Yearbook (pp. 127-140).

Hart, L. C., Alston, A., \& Murata, A. (2011). Lesson Study research and practice in mathematics education. New York: Springer.

Lee, Y. A., \& Takahashi, A. (2011). Lesson plans and the contingency of classroom interactions. Human Studies, 34(2), 209-227.

Lewis, C. (2002). Lesson Study: A handbook of teacher-led instructional change. Philadelphia, PA: Research for Better Schools Inc.

Lewis, C., \& Hurd, J. (2011). Lesson Study step by step: How teacher learning communities improve instruction. Portsmouth, $\mathrm{NH}$ : Heinneman.

Lewis, C., Perry, R., \& Hurd, J. (2009). Improving mathematics instruction through Lesson Study: A theoretical model and North American case. Journal of Mathematics Teacher Education, 12, 285-304.

Lewis, C., \& Tsuchida, I. (1998). A lesson is like a swiftly flowing river. American Educator, 22(4), 12-17; 50-52.

Makinae, N. (2010). The origin of Lesson Study in Japan. In Y. Shimizu, Y. Sekiguchi, \& K. Hino (Eds.), The proceedings of the 5th East Asia regional conference on mathematics education: In search of excellence of mathematics education (vol. 2, pp. 140147). Tokyo: Japan Society of Mathematics Education (JSME).

National Course of Study (in Japanese). (2008). Ministry of education, culture, sports, science and technology. Retrieved April 30, 2015, from http://www.mext.go.jp/a_menu/shotou/cs/index.htm.

Ohtani, M. (2014). Construction zone for the understanding of simultaneous equations An analysis of one Japanese teacher's strategy of reflection on a task in a lesson sequence. In F. K. S. Leung, K. Park, D. Holton, \& D. Clarke (Eds.), Algebra teaching around the world (pp. 113-128). Rotterdam: Sense Publishers.

Ono, Y., \& Ferreira, J. (2010). A case study of continuing teacher professional development through Lesson Study in South Africa. South African Journal of Education, 30(1), 59-74.

Sacks, H. (1992). Lectures on conversation. Cambridge: Blackwell.

Sacks, H., Schegloff, E., \& Jefferson, G. (1974). A simplest systematics for the organization of turn-taking for conversation. Language, 50(4), 693-730.

Shimizu, Y. (1999). Aspects of mathematical teacher education in Japan: Focusing on the teachers' roles. Journal of Mathematics Teacher Education, 2, 107-116.

Stigler, J., \& Hiebert, J. (1999). The teaching gap: Best ideas from the world's teachers for improving education in the classroom. New York: The Free Press.

Takahashi, A. (2006). Types of elementary mathematics Lesson Study in Japan: Analysis of features and characteristics (in Japanese). Journal of Japan Society of Mathematical Education, Mathematics Education, 88(8), 2-14.

Takahashi, A. (2008). Beyond show and tell: Neriage for teaching through problem-solving-Ideas from Japanese problem-solving approaches for teaching mathematics. Paper presented at the 11th International Congress on Mathematics Education in Mexico (Section TSG 19: Research and Development in Problem Solving in Mathematics Education), Monterrey, Mexico.

Takahashi, A. (2013). Investigation of the mechanism of Lesson Study as the core of the mathematics teacher professional development (in Japanese). In Proceedings of first annual spring conference of Japan Society of Mathematical Education (pp. 83-87).

Takahashi, A., \& McDougal, T. (2014). Implementing a New National Curriculum: A Japanese public school's two-year Lesson-Study project. In Using research to improve instruction, annual perspective in mathematics education, NCTM (pp. 13-21).

Watanabe, T., Takahashi, A., \& Yoshida, M. (2008). Kyozaikenkyu: A critical step for conducting effective Lesson Study and beyond. In F. Arbaugh \& P. M. Taylor (Eds.), Inquiry into mathematics teacher education. Monograph series (vol. 5, pp. 131-142). Association of Mathematics Teacher Educators (AMTE).

White, A. L., \& Lim, C. S. (2008). Lesson Study in Asia Pacific classrooms: Local responses to a global movement. ZDM-The International Journal on Mathematics Education, 40(6), 915-925.

Yoshida, M. (1999). Lesson Study: A case study of a Japanese approach to improving instruction through school-based teacher development. Unpublished doctoral dissertation, University of Chicago, Department of Education. 